\title{
Se-Robô: Aplicativo para Robótica Educacional de Baixo Custo
}

\author{
Lorena Almeida Cunha Ferreira' ${ }^{1}$, Ângelo Magno de Jesus ${ }^{1}$, Maria Caroline \\ Bolivar Rufo' ${ }^{1}$, Fabiano Marinho Cindra Santos ${ }^{1}$
}

\author{
${ }^{1}$ Instituto Federal de Minas Gerais, campus Ouro Branco \\ Rua Afonso Sardinha, 90 - Pioneiros - Ouro Branco / MG CEP: 36420-000 \\ lorenacunha.if@gmail.com, angelo.jesus@ifmg.edu.br, \\ carolrufo@hotmail.com, fabianomarcs@gmail.com
}

\begin{abstract}
This paper describes the Se-Robô app and some experimental partial results. Se-Robô is an app part of a low-cost robotics kit. Through SeRobô, students may be interested and learn robotics programing and related concepts in an easy and ludic way. Partial results have shown that the app could help to include educative robotics in the primary schools.
\end{abstract}

Resumo. Este artigo apresenta o aplicativo Se-Robô e alguns resultados parciais alcançados na experiência de sua aplicação. O Se-Robô é um aplicativo que faz parte de um kit de robótica de baixo custo, no qual os alunos poderão se interessar e aprender programação e conceitos relacionados a robótica, de maneira fácil e divertida. Os resultados parciais têm mostrado que o aplicativo poderá facilitar a inclusão de robótica educacional nas escolas de ensino básico.

\section{Introdução}

Seja aplicada de forma interdisciplinar, seja como disciplina independente, a robótica tem trazido grandes avanços para o ensino. Bezerra Neto et al. (2015) relatam que " $a$ interação (proveniente da Robótica Educacional) cria uma atmosfera de interesse e envolvimento (...) no qual os estudantes vivenciam de forma prática conceitos anteriormente vistos em sala de aula". Lessa et. al (2015) também pontuam várias vantagens da Robótica Educacional, entre elas está "trabalho em equipe, colaboração, autodesenvolvimento, capacidade de solucionar problemas, senso crítico, integração de disciplinas, exposição de pensamentos, argumentação, criatividade, autonomia $e$ responsabilidade, postura empreendedora, entre outras". Diante destas vantagens, ainda é o um desafio incluir a robótica educacional de maneira efetiva nas escolas de ensino básico. A maior parte das abordagens incluem a utilização de kits de robótica Lego [Bezerra Neto et al. 2015] que são de padrão proprietário e possuem preços muitas vezes inacessíveis para as instituições de ensino brasileiras. Soma-se a este fato a utilização de laboratórios de Informática com computadores de ponta. Neste contexto, apresentamos o Aplicativo Se-Robô, e o seu kit de robótica, que visa facilitar a inclusão de Robótica Educacional nas escolas de ensino básico de maneira lúdica e econômica.

O Se-Robô se destina principalmente para crianças de 6 a 12 anos de idade e é composto por um aplicativo para dispositivos móveis com sistema Android e um robô móvel de baixo custo desenvolvido na plataforma aberta de hardware Arduino. Através do Se-Robô o estudante poderá programar um robô móvel de maneira intuitiva e 
V Congresso Brasileiro de Informática na Educação (CBIE 2016)

Anais do XXVII Simpósio Brasileiro de Informática na Educação (SBIE 2016)

dinâmica, vendo o resultado de seus comandos em tempo real. Os experimentos iniciais realizados, tem mostrado resultados promissores em relação ao Se-Robô.

\section{Trabalhos Relacionados}

Muitos trabalhos tem sido feitos para inclusão de robótica de baixo custo nas escolas. Miranda et al. (2010) apresentam o desenvolvimento de um Kit de Robótica Educacional adequado para a realidade brasileira. Os autores propõem o kit RoboFácil, o qual é composto por uma implementação de software e hardware. Alves et al. (2014) apresentam o DuinoBlocks, um ambiente de programação visual para robótica educacional. O DuinoBlocks foi projetado para plataforma Arduino e visa facilitar a programação para iniciantes, tendo como público alvo professores e alunos de escolas públicas brasileiras parceiros do Programa Um Computador por Aluno do Governo Federal. (Mesmo autores do artigo) propõem um ambiente para programação em português estruturado de robôs de baixo custo, desenvolvidos na plataforma Arduino. A ideia do ambiente é aproximar estudantes brasileiros da programação não visual para Arduino. O Se-Robô se diferencia dos trabalhos citados anteriormente, por ser focado em plataformas móveis e não em computadores do tipo desktop. Além disso, o Se-Robô apresenta um ambiente de programação simples e interativo focado em um público mais infantil. Codie (2016) é um robô que pode ensinar princípios de programação para crianças. O robô Codie também foi desenvolvido na plataforma Arduino e possui um aplicativo para realizar sua programação de maneira fácil. No entanto, o Codie foi desenvolvido para a realidade de países mais desenvolvidos, se tornando inviável para estudantes brasileirospor possuir um preço mais elevado devido a quantidade de sensores e dispositivos incorporados ao robô e, além disso, o aplicativo de programação, que está na lingua inglesa, possui uma forma de programação menos simplificada que a do Se-Robô.

\section{Metodologia e Desenvolvimento}

O Se-Robô foi implementado utilizando metodologias ágeis de desenvolvimento de software, o que tornou possível uma rápida obtenção de resultados. O sistema, como um todo, funciona em uma arquitetura simples, como ilustra a Figura 1, o aplicativo SeRobô lista os comandos de programação dado pelo usuário e os envia, via rede sem fio, para o robô em formato de flags. O Arduino deverá receber cada flag e converter no movimento correspondente do robô. A conexão se dá de maneira remota através da tecnologia bluetooth.

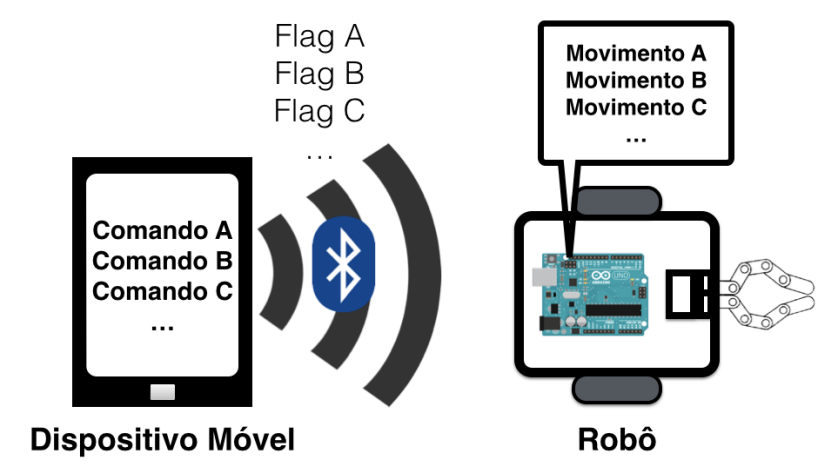

Figura 1. Funcionamento geral do Se-Robô. 
V Congresso Brasileiro de Informática na Educação (CBIE 2016)

Anais do XXVII Simpósio Brasileiro de Informática na Educação (SBIE 2016)

\subsection{O Aplicativo}

O aplicativo foi desenvolvido para dispositivos com sistema operacional Android. Pretende-se portar o aplicativo para os demais sistemas operacionais, no entanto, o Android foi escolhido inicialmente devido a grande aquisição e popularidade de aparelhos com este sistema no Brasil. A Figura 2 (a) ilustra a interface de programação do Se-Robô. O usuário poderá enviar os comandos de controle que se encontram na parte esquerda do aplicativo. Dentre estes comandos se encontram: direcionais, frente, esquerda, direita, trás; repita até encontrar um obstáculo; desvie do obstáculo e abre/ feche a garra. Na parte direita da interface, o usuário poderá visualizar a sequência de comandos informados. Esta sequência poderá ser salva como um arquivo de código e ser carregada novamente. Os comandos são executados em tempo real, para tornar a programação do robôs através do aplicativo mais dinâmica e manter a atenção do jovem usuário.

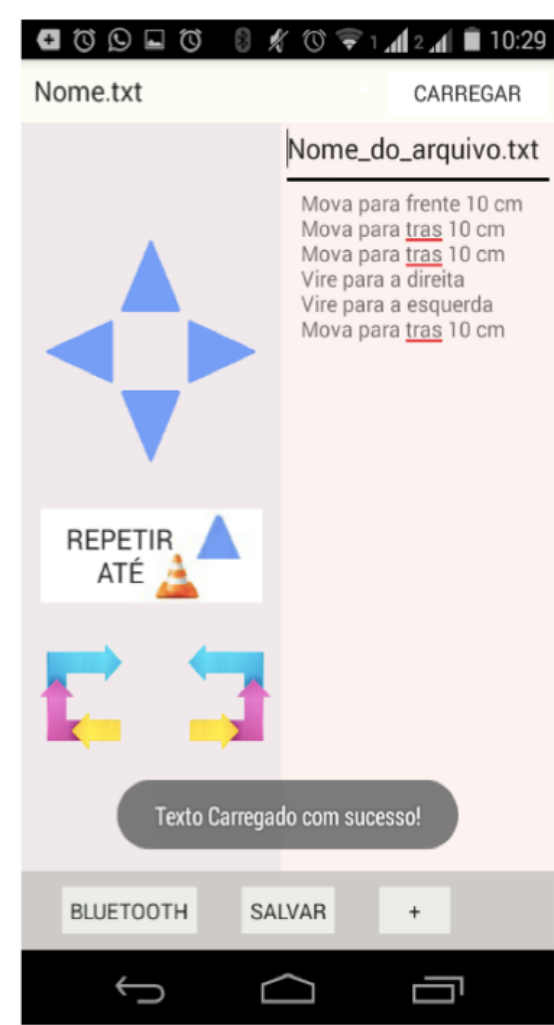

(a)

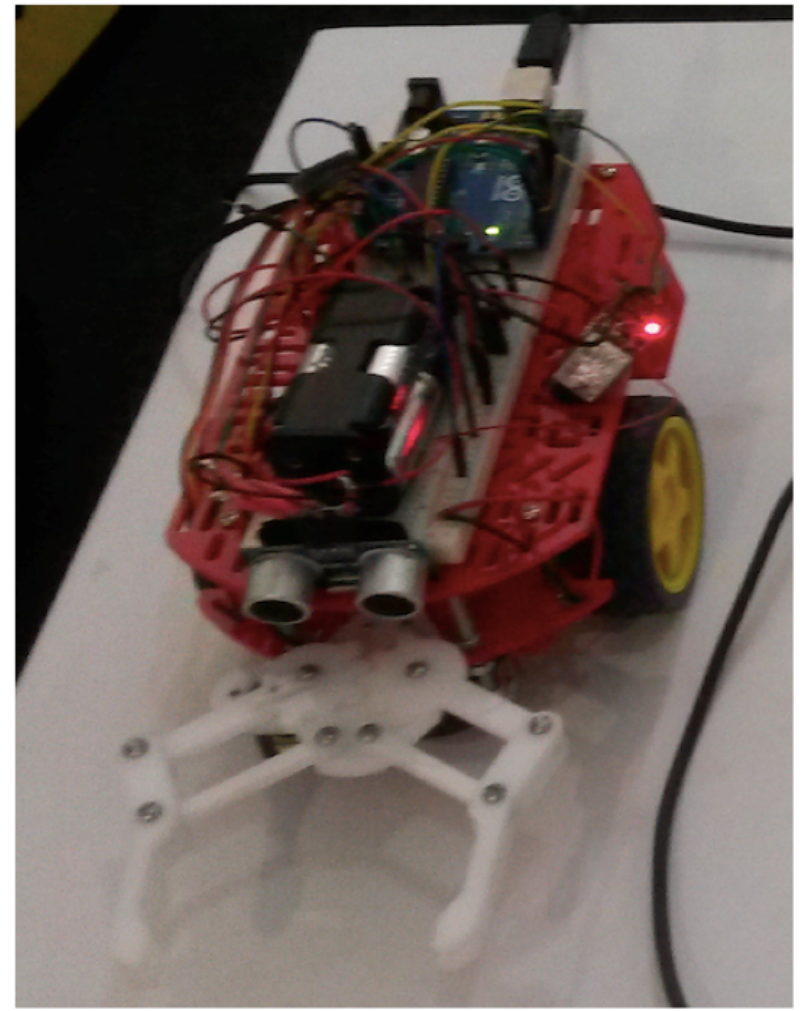

(b)

Figura 2. (a) Interface Gráfica do Aplicativo Se-Robô. (b) Exemplo de robô que pode ser controlado pelo Se-Robô.

\subsection{O Robô}

Como explicado anteriormente, o robô foi desenvolvido na plataforma Arduino, por ser uma plataforma aberta e de baixo custo que está se popularizando rapidamente. Foram utilizadas peças e dispositivos de baixo custo em toda sua montagem. O robô é composto basicamente por: um controlador Arduino, dois motores do tipo DC para locomoção; uma ponte $\mathrm{H}$, para controle dos motores DC; uma garra de acrílico, um 
V Congresso Brasileiro de Informática na Educação (CBIE 2016)

Anais do XXVII Simpósio Brasileiro de Informática na Educação (SBIE 2016)

micro-servo, para controle da garra; um sensor do tipo ultrassônico para desvio de obstáculos e um módulo bluetooth para comunicação com o dispositivo móvel. Ao total, foram gastos cerca de $\mathrm{R} \$ 300,00$ na montagem do robô. A Figura 1 (b) ilustra o robô desenvolvido.

\subsection{Proposta Pedagógica}

Existem várias possibilidades de aplicação do Se-Robô em sala de aula. Por exemplo, sob a orientação do professor, os alunos podem realizar a programação para que o robô passe por obstáculos, utilizando os recursos de loop e direcionais do Se-Robô. Após isso, os estudantes poderiam medir os movimentos do robô de acordo com a sequência da comandos visualizada no aplicativo. Esta atividade pode estimular o raciocínio lógico e a noção de espaço, forma e geometria nas aulas de matemática.

\section{Resultados Parciais}

O Se-Robô foi desenvolvido com sucesso e tem mostrado bons resultados na interação com seus usuários. O aplicativo foi experimentado durante a Mostra Nacional de Robótica 2016 (MNR) e durante o evento Genuino Day. O primeiro evento reuniu não só entusiastas em robótica mas também um público leigo que não conhecia o assunto, mas que mantinha uma certa curiosidade sobre o mesmo, entre este público se encontravam várias crianças que estavam na faixa etária indicada para o Se-Robô. O segundo evento possuía predominantemente um público de profissionais, e estudantes de nível técnico ou superior, todos entusiastas de robótica. Em ambos os eventos o aplicativo demonstrou ser bem aceito pelo público. Por volta de 50 pessoas interagiram com o robô. A Figura 3 mostra alguns usuários interagindo com o Se-Robô, o rosto destas pessoas foi ocultado para não haver exposição das mesmas.
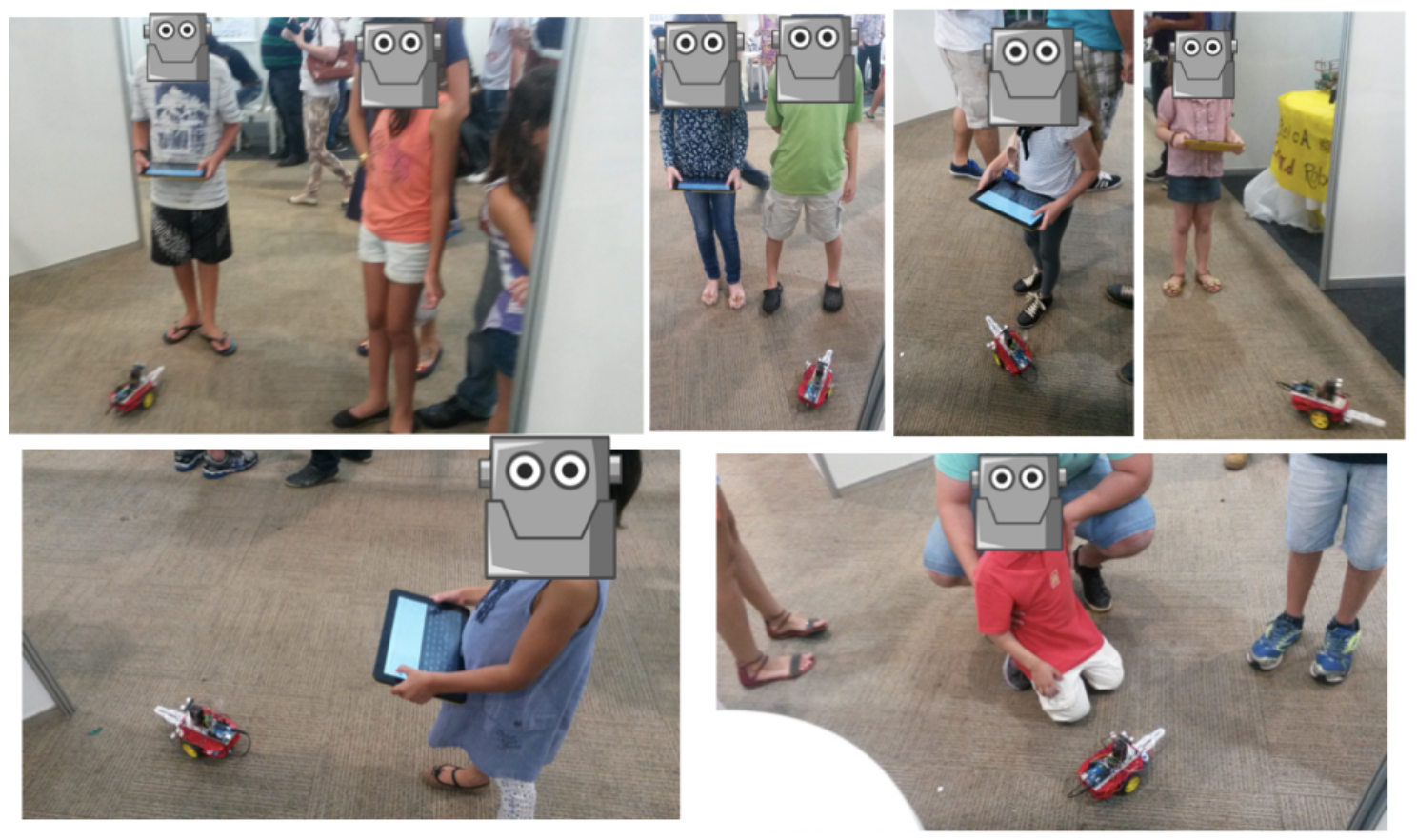

Figura 3. Usuários interagindo com o Se-Robô. 
V Congresso Brasileiro de Informática na Educação (CBIE 2016)

Anais do XXVII Simpósio Brasileiro de Informática na Educação (SBIE 2016)

Em geral, pôde-se observar os seguintes atributos na interação dos usuários:

(a) Interesse: o projeto chamou a atenção da maior parte dos visitantes, principalmente de crianças que se enquadram no público alvo;

(b) Usabilidade: usuários precisavam de poucas instruções para utilizar o aplicativo, bastava mostrar a interface e informar sucintamente o que cada comando significava;

(c) Engajamento: os usuários ao iniciar a interação com o Se-Robô se engajavam em explorar os comandos da interface e em realizer pequenas tarefas com o robô;

(d) Diversão: foram notadas expressões de empolgação e felicidade, principalmente em crianças, na utilização do robô.

A respeito do robô, pode-se considerar o valor de $\mathrm{R} \$ 300,00$ um valor acessível e praticável uma vez que, alguns kits de robótica proprietários são comercializados com valor até dez vezes maior.

\section{Conclusões e Trabalhos Futuros}

O Se-Robô demonstrou ser bastante promissor para interessar e engajar crianças em aprender Robótica e Programação. Entre as vantagens do Se-Robô se encontra (a) utilização de plataformas móveis dispensado laboratórios de informática, (b) ser economicamente acessível, (d) interface fácil de se usar com comandos simples e (e) interação direta com o robô. Como trabalhos futuros, pretende-se fazer a aplicação do Se-Robô em salas de aula de escolas públicas de ensino básico.

\section{Referências}

Alves, R. M., Sampaio, F. F. e Elia M. da F. (2014) "DuinoBlocks: Desenho e Implementação de um Ambiente de Programação Visual para Robótica Educacional". In: Revista Brasileira de Informática na Educação, V. 22, N. 3.

Bezerra Neto, R. P.; Rocha, S. P. ; Santana, A. M. e Souza, A. A. de S. (2015) "Robótica na Educação: Uma Revisão Sistemática dos Últimos 10 Anos". In: Anais do XXVI Simpósio Brasileiro de Informática na Educação (SBIE 2015).

Codie. (2016) "Codie: The robotic toy that teaches kids the principles of coding" http:// www.getcodie.com/, Abril.

Lessa, V. E.; Forigo, F. M., Teixira, A. C. e Licks, G. P. (2015) "Programação de Computadores e Robótica Educativa na Escola: tendências evidenciadas nas produções do Workshop de Informática na Escola". In: Anais do XXI Workshop de Informática na Escola (WIE 2015).

Miranda, L. C.; Sampaio, F. F. e Borges, J. A. dos S. (2010) "RoboFácil: Especificação e Implementação de um Kit de Robótica para a Realidade Educacional Brasileira". In: Revista Brasileira de Informática na Educação, V. 18, N. 3. 